\title{
Korean Scutellaria baicalensis Georgi flavonoid extract induces mitochondrially mediated apoptosis in human gastric cancer AGS cells
}

\author{
VENU VENKATARAME GOWDA SARALAMMA ${ }^{1 *}$, HO JEONG LEE ${ }^{1 *}$, GYEONG EUN HONG ${ }^{1}$, \\ HYEON SOO PARK ${ }^{1}$, SILVIA YUMNAM ${ }^{1}$, SUCHISMITA RAHA ${ }^{1}$, WON SUP LEE ${ }^{2}$, EUN HEE KIM ${ }^{3}$, \\ NAK JU SUNG ${ }^{4}$, SANG JOON LEE ${ }^{5}$, JEONG DOO HEO ${ }^{5}$ and GON SUP KIM ${ }^{1}$ \\ ${ }^{1}$ Research Institute of Life Science and College of Veterinary Medicine, Gyeongsang National University, \\ Jinju, Gyeongsangnam 660-701; ${ }^{2}$ Department of Internal Medicine, Institute of Health Sciences, Gyeongsang \\ National University School of Medicine, Gajwa, Gyeongsangnam 660-702; ${ }^{3}$ Department of Nursing Science, \\ International University of Korea, Jinju, Gyeongsangnam 660-759; ${ }^{4}$ Department of Food and Nutrition, \\ Gyeongsang National University, Jinju, Gyeongsangnam 660-701; ${ }^{5}$ Gyeongnam Biological Resource \\ Research Center, Korea Institute of Toxicology, Jinju, Gyeongsangnam 666-844, Republic of Korea
}

Received December 24, 2015; Accepted February 23, 2017

DOI: 10.3892/ol.2017.6184

\begin{abstract}
Korean Scutellaria baicalensis Georgi has been widely used in Korean folk medicines for its range of medicinal benefits, including its anticancer effect. The aim of the present study was to investigate the underlying molecular mechanism of action of a flavonoid extract from Korean Scutellaria baicalensis Georgi (FSB) on AGS human gastric cancer cells (gastric adenocarcinoma) in which FSB exhibits an anticancer effect. Treatment of AGS cells with FSB significantly inhibited cell viability in a concentration-dependent manner. Furthermore, FSB significantly increased the proportion of cells in sub- $\mathrm{G}_{1}$ phase, and Annexin $\mathrm{V}$ and Hoechst 33258 fluorescent staining confirmed the apoptotic cell death. Furthermore, western blotting results identified that treatment of AGS cells with FSB significantly downregulated the expression of caspase family members, namely procaspases 3
\end{abstract}

Correspondence to: Professor Gon Sup Kim, Research Institute of Life Science and College of Veterinary Medicine, Gyeongsang National University, 900 Gajwa-dong, Jinju, Gyeongsangnam 660-701, Republic of Korea

E-mail: gonskim@gnu.ac.kr

Dr Jeong Doo Heo, Gyeongnam Biological Resource Research Center, Korea Institute of Toxicology, 17 Jegok-gil, Jinju, Gyeongsangnam 666-844, Republic of Korea

E-mail: jdher@kitox.re.kr

"Contributed equally

Key words: apoptosis, B cell lymphoma 2-associated X protein/B cell lymphoma extra large ratio, gastric cancer, flavonoids, Korean Scutellaria baicalensis Georgi and 9, and poly(ADP-ribose) polymerase (PARP), and subsequently upregulated cleaved caspase 3 and cleaved PARP. It was observed that FSB treatment significantly decreased the mitochondrial membrane potential of AGS cells. In addition, the ratio of the mitochondrion-associated proteins $\mathrm{B}$ cell lymphoma 2-associated X protein and B cell lymphoma extra large was upregulated. The results of the present study provide novel insight into the underlying molecular mechanism of the anticancer effects of FSB on AGS human gastric cancer cells and indicate that FSB may be an alternative chemotherapeutic agent for the treatment of gastric cancer.

\section{Introduction}

Gastric cancer is one of the most common malignancies worldwide, with an estimated 951,600 novel stomach cancer cases and 723,100 mortalities occurring in 2012 (1). Treatment options currently available for gastric cancer are inadequate. Recent advances in surgical techniques have led to an increase in the 5-year survival rate of patients with gastric cancer from 10 to $30 \%$. However, patients with gastric cancer in advanced stages are untreatable (2-5). Therefore, there is an urgent requirement to identify novel therapeutic agents that can decrease the mortality of cancer patients with fewer side effects.

Natural products have been identified to exhibit anticancer effects by targeting multiple cellular signaling pathways, mediated by complex signal transduction (5). In our previous studies, extracts of the herbal plants Citrus aurantium L., Lonicera japonica Thunb. and Scutellaria baicalensis Georgi were identified to exhibit anticancer effects in human gastric, liver and lung cancer cells, respectively (6-8).

Flavonoids are natural polyphenolic compounds extensively present in vegetables and fruits. The use of flavonoids as anticancer compounds has been investigated previously (6). 
In previous a in vitro study, S. baicalensis Georgi extract was reported to be cytotoxic to a broad spectrum of human cancer cell lines (7). In spite of the molecular mechanisms underlying these effects remaining unclear, previous studies suggest that the cytotoxicity of S. baicalensis Georgi regulates the viability of human cancer cells by inducing apoptosis, arresting cell cycle progression and regulating metastasis in various cancer cell lines. S. baicalensis Georgi has been widely used in traditional Chinese herbal medicine to treat inflammation, hypertension and cardiovascular disease, and has officially been listed in the Chinese Pharmacopoeia as a medicinal plant (8-11).

Apoptosis, or type 1 programmed cell death, serves a fundamental role in the normal development and differentiation of multicellular organisms. Activation of apoptosis in cancer cells may be instrumental in the process of cancer cell elimination. There are two primary apoptotic signaling pathways: The extrinsic or death receptor signaling pathway, and the intrinsic or mitochondrial signaling pathway (12). Apoptosis is characterized by cytoplasmic shrinking, extensive plasma membrane blebbing and nuclear condensation formation $(13,14)$. Apoptosis progresses in either a caspase-dependent or a caspase-independent manner (15). Furthermore, the expression ratio of anti- and pro-apoptotic mitochondrial proteins, including B cell lymphoma 2 (Bcl-2) -associated X protein (Bax)/B cell lymphoma extra-large (Bcl-xL), is crucial for the induction of apoptosis, and determines the susceptibility of cells to apoptosis (16).

In the present study, the anticancer effect of flavonoid extract from Korean S. baicalensis Georgi (FSB) was investigated with the aim of elucidating the underlying molecular mechanisms of the anticancer effect of FSB on AGS human gastric cancer cells.

\section{Materials and methods}

Chemicals. RPMI-1640 medium, antibiotics (penicillin/ streptomycin) and fetal bovine serum were purchased from Gibco; Thermo Fisher Scientific, Inc. (Waltham, MA, USA). Antibodies against caspase-3 (\#9662; 1:1,000), caspase-9 (\#9502; 1:1,000), cleaved caspase-3 (\#9664; 1:1,000), poly (ADP-ribose) polymerase (PARP) (\#9542; 1:1,000), cleaved PARP (\#5625; 1:1,000), tumor necrosis factor regulator superfamily member 6 (Fas) (\#4233; 1:500), Fas ligand (FasL) (\#4273; 1:500), Bcl-xL (\#2764; 1:1,000) and Bax (\#2774; 1:1,000) were purchased from Cell Signaling Technology, Inc. (Danvers, MA, USA). Anti- $\beta$-actin antibody was obtained from EMD Millipore (\#MAB-1501; 1:10,000; Billerica, MA, USA). Anti-rabbit IgG (\#ADI-SAB-300; 1:2,000) and horseradish peroxidase-conjugated goat anti-mouse IgG (\#ADI-SAB-100-J; 1:2,000) were purchased from Enzo Life Sciences (Postfach CH-4415 Lausen, Switzerland). MTT was obtained from Sigma-Aldrich; Merck KGaA (Darmstadt, Germany). An Annexin V-fluorescein isothiocyanate (FITC) apoptosis detection kit (FITC Annexin V Apoptosis Detection kit I) was purchased from BD Pharmingen (San Diego, CA, U.S.A.). Propidium iodide (PI) was procured from Sigma-Aldrich (Merck KGaA). A caspase- 8 activity assay kit (Caspase 8 Colorimetric Activity Assay kit, IETD) was purchased from EMD Millipore (Billerica, MA, USA),
Hoechst 33342 trihydrochloride stain was purchased from Invitrogen; Thermo Fisher Scientific (Eugene, OR97402). Electrophoretic materials and chemicals were procured from Bio-Rad Laboratories, Inc. (Hercules, CA, USA).

Isolation of flavonoids from Korean S. baicalensis Georgi. Korean S. baicalensis Georgi radix was obtained from the Animal Bioresources Bank (Jinju, Korea). The flavonoids were isolated using HPLC-tandem mass spectrometry (MS/MS) at the Department of Chemistry, Gyeongsang National University (Jinju, Korea) by Professor Sung Chul Shin. The sample was prepared according to a previously described method (16). Samples were stored at $-20^{\circ} \mathrm{C}$ until use.

Cell culture. Human gastric cancer AGS cells were obtained from the Korea Cell Line Bank (Seoul, Korea) and cultured and maintained in RPMI-1640 medium supplemented with $10 \%$ (v/v) heat-inactivated fetal bovine serum and $1 \%$ penicillin/ streptomycin in a humidified atmosphere with $5 \% \mathrm{CO}_{2}$ at $37^{\circ} \mathrm{C}$.

Cell viability assay. To assess the effect of FSB on AGS cell viability, cells were seeded $\left(1 \times 10^{5}\right.$ cells $\left./ \mathrm{ml}\right)$ on a 12 -well plate and were treated with 50, 100, 200 and $400 \mu \mathrm{g} / \mathrm{ml} \mathrm{FSB}$ or vehicle (DMSO) alone for $24 \mathrm{~h}$ at $37^{\circ} \mathrm{C}$. A $100 \mu \mathrm{l}$ volume of MTT solution $(0.5 \mathrm{mg} / \mathrm{ml})$ was subsequently added to each well prior to incubation at $37^{\circ} \mathrm{C}$ for $3 \mathrm{~h}$. The culture medium was removed and $500 \mu \mathrm{l}$ dimethylsulfoxide (DMSO) was added to each well to dissolve the formazan crystals that had formed. Following mixing, absorbance was determined at $540 \mathrm{~nm}$ using a plate reader (Bio-Rad Laboratories, Inc.). Cell viability was expressed as a percentage of viability relative to that of the vehicle-treated control, which was set as $100 \%$.

Cell cycle distribution and measurement of cell apoptosis. AGS cells were seeded in $60-\mathrm{mm}$ dishes $\left(1 \times 10^{5}\right.$ cells $\left./ \mathrm{ml}\right)$ and incubated at $37^{\circ} \mathrm{C}$. When cells had reached between 70 and $80 \%$ confluence, they were treated with 0,50 and $100 \mu \mathrm{g} / \mathrm{ml}$ FSB added directly to the culture medium and incubated at $37^{\circ} \mathrm{C}$ for $24 \mathrm{~h}$. Following incubation, whole cells were harvested by trypsinization and washed with ice-cold PBS and fixed in $70 \%$ ethanol at $-20^{\circ} \mathrm{C}$ for $1 \mathrm{~h}$. Fixed cells were washed in PBS and stained with PI $(50 \mu \mathrm{g} / \mathrm{ml})$ including RNase A $(0.1 \mathrm{mg} / \mathrm{ml})$ in PBS for $30 \mathrm{~min}$ in the dark. Flow cytometry analyses were performed using a Cytomics FC 500 flow cytometer (Beckman Coulter, Inc., Brea, CA, USA). In each sample, 10,000 cells were analyzed. Data were analyzed using CXP software (version 2.2; Beckman Coulter, Inc.).

Annexin V-PI apoptosis detection assay. AGS cells were treated with various concentrations of $\operatorname{FSB}(0,50$ and $100 \mu \mathrm{g} / \mathrm{ml})$ for $24 \mathrm{~h}$ at $37^{\circ} \mathrm{C}$. Cells were harvested by trypsinization and washed with PBS, then resuspended in binding buffer [0.1 M Hepes/NaOH (pH-7.4), 1.4 M NaCl, 25 mM CaCl${ }_{2}$ ]. Cells were stained with Annexin V-FITC and PI for $15 \mathrm{~min}$ at room temperature in the dark, and $500 \mu \mathrm{l}$ binding buffer was added. The stained apoptotic cells were measured using a FACSCalibur flow cytometer (BD Biosciences, Franklin Lakes, NJ, USA). In each sample, 10,000 cells were analyzed. The data were analyzed using Cell Quest software (version 7.5.3; BD Biosciences). 
Hoechst 33,258 staining. Cell nuclear morphology was eval uated using fluorescence microscopy following Hoechst 33,258 DNA staining. AGS cells were seeded ( $1 \times 10^{5}$ cells $\left./ \mathrm{ml}\right)$ on coverslips and treated with treated or not with $100 \mu \mathrm{g} / \mathrm{ml}$ FSB for $24 \mathrm{~h}$ at $37^{\circ} \mathrm{C}$. The cells were then washed in ice-cold PBS and fixed in $3.7 \%$ paraformaldehyde solution for $15 \mathrm{~min}$ at room temperature. The cells were stained with Hoechst $33258(5 \mu \mathrm{g} / \mathrm{ml}$ in PBS$)$ for $10 \mathrm{~min}$ at room temperature and structural changes were observed using a fluorescence microscope (Leica Microsystems, Ltd., Milton Keynes, UK).

Measurement of mitochondrial membrane potential. AGS cells were incubated with or without FSB at various concentrations $(0,50$ and $100 \mu \mathrm{g} / \mathrm{ml})$ at $37^{\circ} \mathrm{C}$ for $24 \mathrm{~h}$ in RPMI-1640 medium. After $24 \mathrm{~h}$ of incubation, cells were harvested by trypsinization and washed with $1 \mathrm{X}$ PBS. Washed cells were stained with 3,3'-dihexyloxacarbocyanine iodide (DiOC6) dye and the change in fluorescent intensity was analyzed using a Cytomics FC 500 flow cytometer. In each sample, 10,000 cells were analyzed. The data were analyzed using CXP software.

Caspase- 8 activity assay. Caspase- 8 activity was determined using a colorimetric assay with a caspase- 8 activity kit, according to the manufacturer's protocol. AGS cells were incubated with or without FSB at various concentrations $(0,50$ and $100 \mu \mathrm{g} / \mathrm{ml})$ at $37^{\circ} \mathrm{C}$ for $24 \mathrm{~h}$ in complete medium. After $24 \mathrm{~h}$ of incubation, cells were harvested by trypsinization and lysed using lysis buffer supplied in the kit and incubated for $10 \mathrm{~min}$ in an ice bath. Subsequently, samples were centrifuged at $10,000 \mathrm{x} \mathrm{g}$ for $5 \mathrm{~min}$ in a microcentrifuge. The supernatants were collected and incubated at $37^{\circ} \mathrm{C}$ for $1 \mathrm{~h}$ with assay buffer and caspase- 8 substrate $(\mathrm{N}-\mathrm{ac}$ etyl-Ile-Glu-Thr-Asp-p-nitroanilide) supplied in the kit. The optical density of the reaction mixture was quantified using a plate reader at $405 \mathrm{~nm}$.

Determination of proteins involved in the apoptotic signaling pathway using western blot analysis. AGS cells were treated with various concentrations of FSB $(0,50$ and $100 \mu \mathrm{g} / \mathrm{ml})$ at $37^{\circ} \mathrm{C}$ for $24 \mathrm{~h}$ and cell lysates were prepared using lysis buffer [1\% (w/w) NP40, $1 \%(\mathrm{w} / \mathrm{v})$ sodium deoxycholate, $0.1 \%(\mathrm{w} / \mathrm{v})$ SDS, $0.15 \mathrm{M} \mathrm{NaCl}, 0.01 \mathrm{M}$ sodium phosphate buffer, $\mathrm{pH}$ 7.2, 2 mM EDTA and protease inhibitors (Thermo Fisher Scientific, Inc.)]. Protein lysates were centrifuged at $14,500 \mathrm{x} \mathrm{g}$ for $15 \mathrm{~min}$ at $4^{\circ} \mathrm{C}$ to remove insoluble material. The protein concentration in the supernatants was determined using a Bradford protein assay kit (Bio-Rad Laboratories, Inc.), according to the manufacturer's protocol. A total of $50 \mu \mathrm{g}$ of proteins were separated by SDS-PAGE (12\% gel) and transferred onto a polyvinyldene fluoride membrane using a TE 77 Semi-Dry Transfer Unit (GE Healthcare Life Sciences, Chalfont, UK). Following blocking in 5\% skimmed milk powder in Tris-buffered saline containing Tween-20 for $1 \mathrm{~h}$ at room temperature, membranes were incubated overnight with primary antibodies at $4{ }^{\circ} \mathrm{C}$ followed by incubation for $3 \mathrm{~h}$ with horseradish peroxidase-conjugated secondary antibody at room temperature. Blots were developed using an enhanced chemiluminescence detection system (GE Healthcare Life Sciences). Bands were quantitatively analyzed using the ImageJ $1.50 \mathrm{i}$ program (rsb.info.nih.

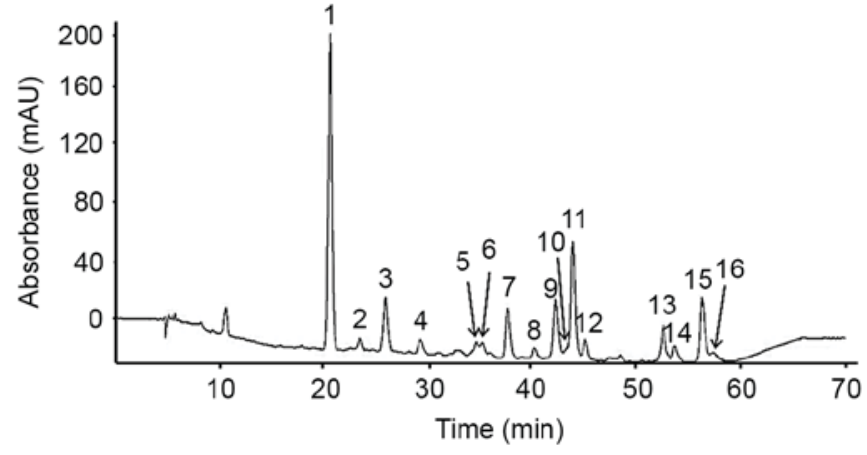

Figure 1. HPLC profiles at $280 \mathrm{~nm}$ of the flavonoid extract from Korean Scutellaria baicalensis Georgi. Peaks: (1) Pentahydroxyflavanone derivative; (2) pentahydroxyflavanone; (3) viscidulin I-O-diglucoside; (4) pentahydroxyflavone; (5) unidentified; (6) viscidulin III-O-glucoside; (7) tetrahydroxyflavone; (8) iridin; (9) eriodictyol (4'-hydroxynaringenin); (10) puerarin; (11) viscidulin III; (12) pentahydroxyflavone; (13) unidentified; (14) baicalin; (15) scutellarein; (16) isoscutellarein. mAU, milli-absorbance units

gov), normalized to $\beta$-actin expression. Experiments were performed three times.

Statistical analysis. All statistical analyses were performed using SPSS software for Windows (version 10.0; SPSS, Inc., Chicago, IL, USA). Results are presented as the mean \pm standard deviation of at least three independent experiments. The statistical significance between the control and test groups was determined using one-way analysis of variance followed by Student's t-test. $\mathrm{P}<0.05$ was considered to indicate a statistically significant difference.

\section{Results}

Characterization and quantification of FSB. Flavonoids were isolated from Korean S. baicalensis Georgi using HPLC-MS/MS. A total of 16 peaks at $280 \mathrm{~nm}$ were identified on the basis of the HPLC retention time, molecular ion masses and the ultraviolet-visible spectra of a library of standard compounds (Fig. 1). The mass spectral and quantification data of the 16 flavonoids are presented in Table I.

FSB inhibits the viability of AGS cells. To determine appropriate inhibitory concentrations of FSB on AGS cells, cells were treated with various concentrations $(0,50,100,200$ and $400 \mu \mathrm{g} / \mathrm{ml}$ ) FSB for $24 \mathrm{~h}$ and an MTT assay was performed to evaluate cell viability. As presented in Fig. 2A, FSB exhi bited a concentration-dependent inhibitory effect on AGS cells compared with the control (DMSO only) at $24 \mathrm{~h}$ and the half-maximal inhibitory concentrations $\left(\mathrm{IC}_{50}\right)$ value was identified to be $\sim 100 \mu \mathrm{g} / \mathrm{ml}$ ( $\mathrm{P}<0.01$ for the FSB-treated groups compared with the control). Previously, FSB demonstrated a cytotoxic effect in AGS human gastric cancer cells, but not in normal cells (9), therefore the cytotoxicity of FSB is cancer cell-specific. In the present study, concentrations of FSB of 0 , 50 and $100 \mu \mathrm{g} / \mathrm{ml}$ were used for further experiments. Further to the results of the MTT assay, microscopic examination revealed morphological changes, including cell shrinkage, floating of dead cells and a decrease in cell numbers were observed in FSB-treated cells (Fig. 2B), as primary indications of apoptosis. 
Table I. List of identified flavonoids from Scutellaria baicalensis Georgi and quantification data.

\begin{tabular}{|c|c|c|c|c|c|}
\hline $\begin{array}{l}\text { Peak } \\
\text { no. }\end{array}$ & Compound & $\begin{array}{l}\mathrm{Rt} \\
\mathrm{min}\end{array}$ & $\begin{array}{c}\mathrm{MS} \\
{[M-\mathrm{H}]-}\end{array}$ & MS/MS & $\begin{array}{l}\text { Quantity } \\
(\mathrm{mg} / \mathrm{kg})\end{array}$ \\
\hline 1 & $\begin{array}{l}\text { Pentahydroxyflavanone } \\
\text { derivative }\end{array}$ & 20.64 & 629 & $303,285,275,217,201,177,149,125$ & $174.844 \pm 4.017$ \\
\hline 2 & Pentahydroxyflavanone & 23.49 & 303 & $\begin{array}{l}303,285,275,259,217,193,177,149 \\
125,109\end{array}$ & $14.833 \pm 0.167$ \\
\hline 3 & Viscidulin I-O-diglucoside & 25.98 & 625 & $301,283,273,258,229,185,151,125$ & $23.500 \pm 0.388$ \\
\hline 4 & Pentahydroxyflavone & 29.31 & 301 & $\begin{array}{l}301,283,269,259,240,191,179,161, \\
139,124,121,109\end{array}$ & $14.448 \pm 0.059$ \\
\hline 5 & Unidentified & 34.65 & $647(+)$ & $647,501,467,347,321,303,285$ & - \\
\hline 6 & Viscidulin III-O-glucoside & 35.22 & 507 & $345,330,315$ & - \\
\hline 7 & Tetrahydroxyflavone & 37.69 & 285 & $285,268,241,217,199,177,151,133,107$ & $50.577 \pm 0.158$ \\
\hline 8 & Iridin & 40.20 & 521 & $383,359,344,329,313,300,285,212$ & $16.639 \pm 0.075$ \\
\hline 9 & $\begin{array}{l}\text { Eriodictyol } \\
\text { (4'-hydroxynaringenin) }\end{array}$ & 42.25 & $289(+)$ & $289,271,247,179,163,153,147$ & $23.509 \pm 0.244$ \\
\hline 10 & Puerarin & 43.24 & 415 & $415,295,267,253,223$ & $6.665 \pm 0.045$ \\
\hline 11 & Viscidulin III & 43.88 & $347(+)$ & $347,332,317,314,289,286,183,169,150,142$ & - \\
\hline 12 & Pentahydroxyflavone & 45.11 & 301 & $\begin{array}{l}301,283,269,241,225,197,179,165,161 \\
139,133,124,107\end{array}$ & $16.108 \pm 0.541$ \\
\hline 13 & Unidentified & 52.55 & 675 & $675,529,481,361,335,317,285$ & - \\
\hline 14 & Baicalin & 53.67 & $447(+)$ & $447,343,271,253,225,169,149,123,105$ & $1.998 \pm 0.004$ \\
\hline 15 & Scutellarein & 56.25 & 285 & $\begin{array}{l}285,267,257,239,213,195,185,167,165 \\
137,119,117\end{array}$ & $25.741 \pm 0.119$ \\
\hline 16 & Isoscutellarein & 57.35 & 285 & $\begin{array}{l}285,267,257,241,239,229,213,185,167 \\
165,137,119,117\end{array}$ & $7.143 \pm 0.025$ \\
\hline
\end{tabular}

Rt, retention time; MS, mass spectrometry; MS/MS, tandem MS.

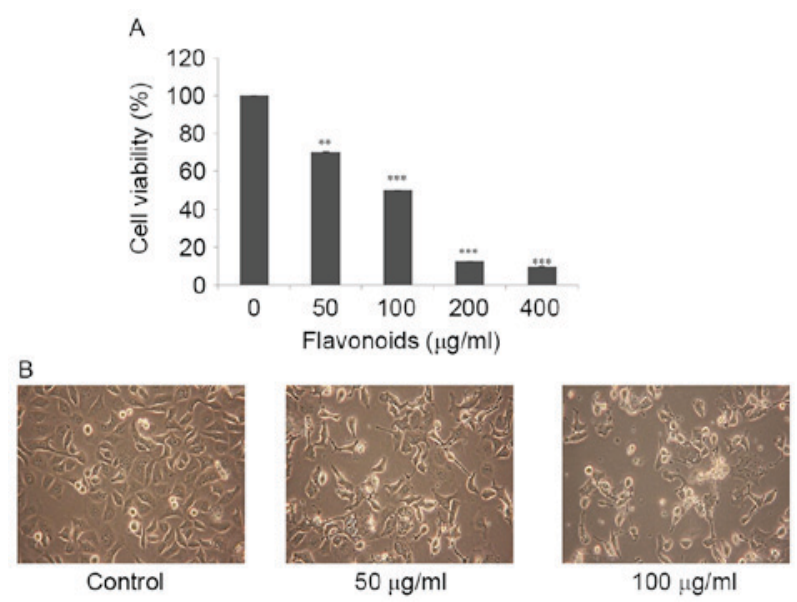

Figure 2. FSB exerts an inhibitory effect on AGS cell viability. AGS cells were treated with the indicated concentrations of FSB for $24 \mathrm{~h}$. (A) Cell viability was determined using an MTT assay. ${ }^{* *} \mathrm{P}<0.05 ;{ }^{* * *} \mathrm{P}<0.01$ vs. control. (B) The morphology of cells was examined using a light microscope (magnification, x400). FSB, flavonoid extract from Korean Scutellaria baicalensis Georgi.

FSB induces sub-G $G_{1}$ phase accumulation and apoptosis. Flow cytometric analysis was performed to determine the cell cycle distribution and the population of cell death in FSB-treated AGS cells. Treatment with FSB increased the proportion of sub- $\mathrm{G}_{1}$ phase content (representing the apoptotic cell population) from 7 to $21 \%(\mathrm{P}<0.05)$ and $27 \%(\mathrm{P}<0.001)$ for 50 and $100 \mu \mathrm{g} / \mathrm{ml}$, respectively; FSB substantially decreased the $G_{0} / G_{1}, S$ and $G_{2} / M$ phase populations (Fig. 3A and B). The effect of FSB on the induction of apoptosis in AGS cells was also assessed using Annexin V-FITC/PI double-labeled flow cytometry (Fig. 4A). FSB significantly increased early apoptotic cell proportions and late apoptotic cell proportions of AGS cells in a concentration-dependent manner $(\mathrm{P}<0.05$; Fig. 4B). Furthermore, apoptosis was confirmed by Hoechest 33342 staining in AGS cells treated with FSB at a concentration of $100 \mu \mathrm{g} / \mathrm{ml}$, with nuclear fragmentation and apoptotic bodies observed (Fig. 4C). These results suggest that FSB may induce apoptotic cell death in AGS cells.

FSB induces the mitochondrial apoptotic signaling pathway in AGS cells. In order to assess the underlying molecular mechanism by which FSB induced apoptotic cell death in AGS cells, western blot analysis of the caspase cascade was performed in AGS cells. The western blot results indicated that the expression of procaspase- 3 and procaspase- 9 was significantly decreased, and, following caspase activation, the expression of cleaved caspase- 3 and cleaved PARP, a substrate of activated caspase-3, was significantly increased in a concentration-dependent manner $(\mathrm{P}<0.05$ or $<0.01$; Fig. 5). However, no significant alterations in total PARP expression in FSB-treated cells were identified. To investigate the 
A

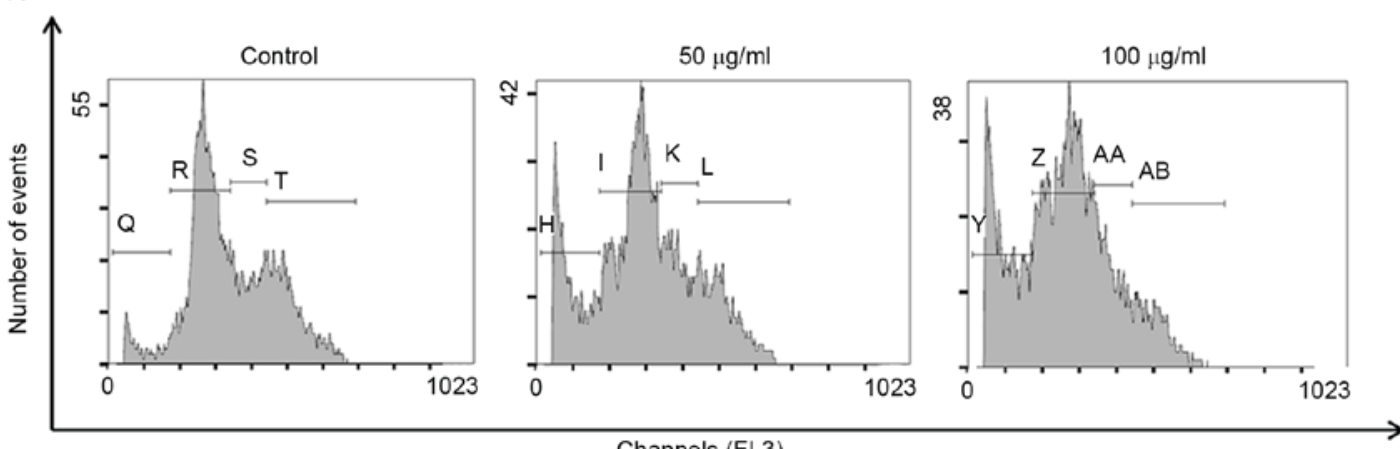

Channels (FL3)

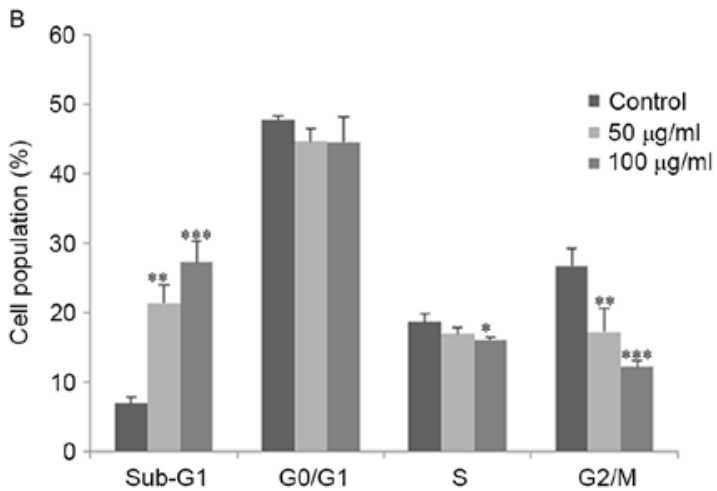

Figure 3. FSB regulates cell cycle progression of AGS cells. AGS cells were treated with the indicated concentrations of FSB for $24 \mathrm{~h}$. (A) Cell cycle distribution was determined using flow cytometry (Q, H, Y-Sub-G $\mathrm{G}_{1}: \mathrm{R}, \mathrm{I}, \mathrm{Z}-\mathrm{G}_{0} / \mathrm{G}_{1}: \mathrm{S}, \mathrm{K}, \mathrm{AA}-\mathrm{S}: \mathrm{T}, \mathrm{L}, \mathrm{AB}-\mathrm{G}_{2} / \mathrm{M}$ cell cycle phase). (B) Histogram representation of cell cycle distribution of AGS cells treated with FSB. ${ }^{*} \mathrm{P}<0.05 ;{ }^{* *} \mathrm{P}<0.01 ;{ }^{* * * *} \mathrm{P}<0.001$ vs. control. FSB, flavonoid extract from Korean Scutellaria baicalensis Georgi.

A
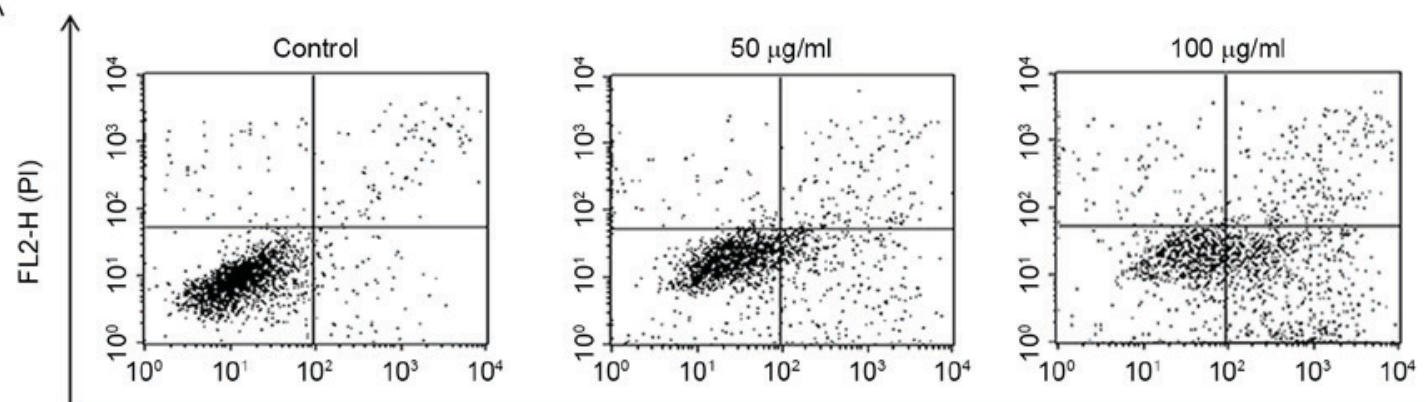

FL1-H (annexin V)

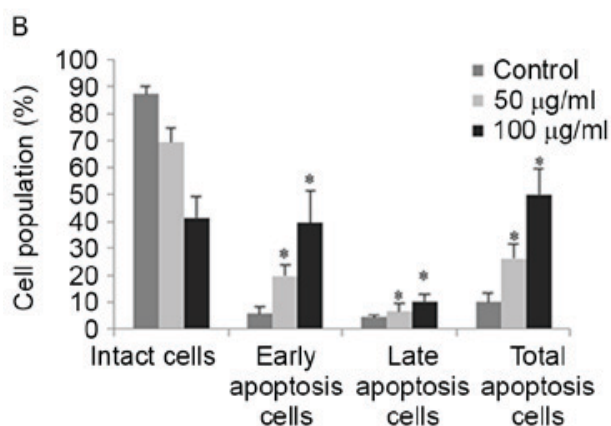

C
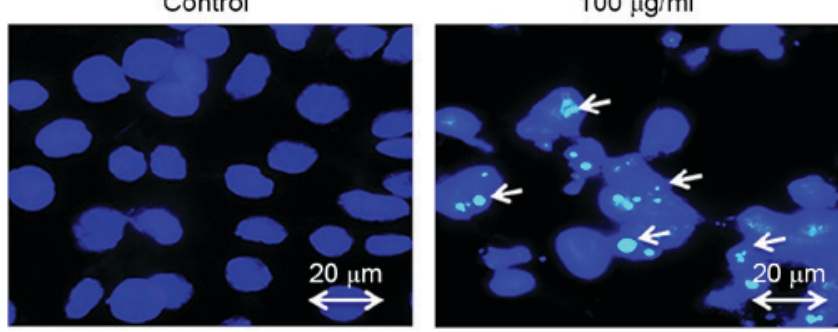

Figure 4. FSB induces concentration-dependent apoptosis in AGS cells. AGS cells were treated with the indicated concentrations of FSB for $24 \mathrm{~h}$. (A) Apoptosis was assessed using Annexin V-PI double staining and flow cytometry. (B) Histogram representation of apoptosis distribution of AGS cells treated with FSB ${ }^{*} \mathrm{P}<0.05$ vs. control. (C) AGS cells were stained with Hoechst 33,258 and analyzed using fluorescence microscopy (x 400). White arrows indicate bright blue regions which are fragmented or condensed nuclei. (FSB- flavonoid extract from Korean Scutellaria baicalensis Georgi; PI, propidium iodide).

effect of FSB on mitochondrial membrane potential, AGS cells untreated or treated with FSG for $24 \mathrm{~h}$ were stained with DiOC6 dye and the alteration in fluorescence intensity was assessed using flow cytometry. It was observed that FSB 

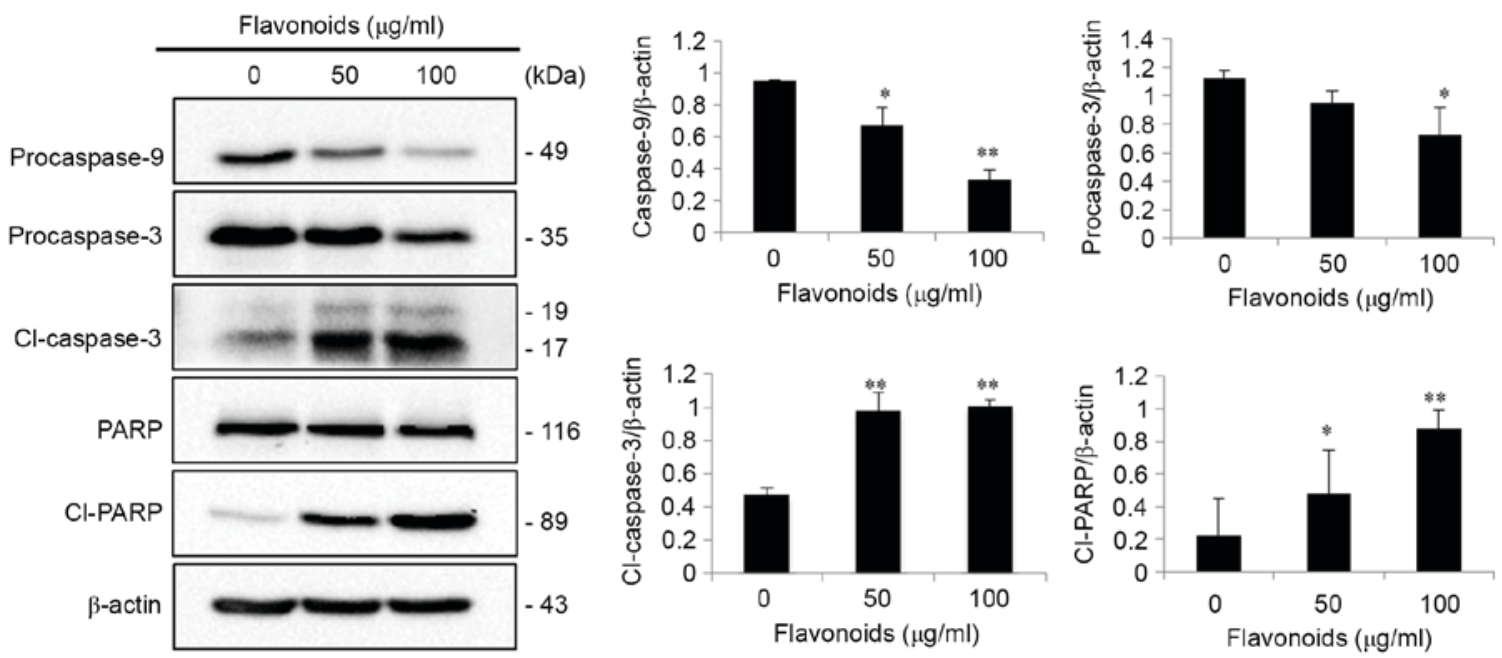

Figure 5. FSB acts via the intrinsic signaling pathway of apoptosis activation in AGS cells. AGS cells were treated with the indicated concentrations of FSB for $24 \mathrm{~h}$. The cell lysates were subjected to SDS-PAGE and analyzed by western blotting. $\beta$-actin was used as a loading control. Protein expression levels of procaspase-3, procaspase-9, Cl-caspase-3, PARP and Cl-PARP were determined using densitometric analysis. ${ }^{~} \mathrm{P}<0.05$; ${ }^{* *} \mathrm{P}<0.01$ vs. control. FSB, flavonoid extract from Korean Scutellaria baicalensis Georgi; PARP, poly(ADP-ribose) polymerase; Cl-, cleaved.
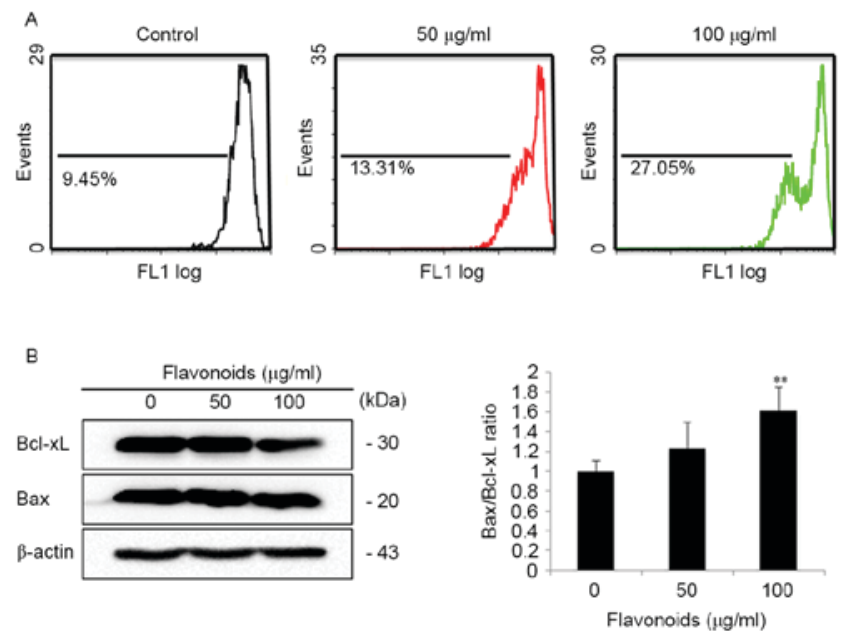

Figure 6. FSB induces apoptosis via the mitochondrial signaling pathway in AGS cells. (A) Decrease in mitochondrial membrane potential induced by FSB. FSB-treated/untreated cells for $24 \mathrm{~h}$ were stained with 3,3'-dihexyloxacarbocyanine iodide stains, and the alteration in fluorescent intensity was determined using flow cytometry. (B) AGS cells were treated with the indicated concentrations of FSB for $24 \mathrm{~h}$. The cell lysates were subjected to SDS-PAGE and analyzed by western blotting. The Bax/Bcl-xL ratio was determined using densitometric analysis. ${ }^{* * *} \mathrm{P}<0.01$ vs. control. FSB, flavonoid extract from Korean Scutellaria baicalensis Georgi; Bax, B cell lymphoma 2-associated X protein; Bcl-xL, B cell lymphoma extra large.

treatment markedly decreased the mitochondrial membrane potential of AGS cells (Fig. 6A). In addition, the expression of the mitochondrion-associated apoptotic proteins Bax and Bcl-xL was also analyzed in FSB-treated AGS cells. FSB increased the expression of the Bax/Bcl-xL ratio of AGS cells in a concentration-dependent manner (Fig. 6B). These results suggest that FSB induced caspase-dependent mitochondrion-mediated apoptosis in AGS cells.

FSB induces apoptosis in AGS cells are independent of the extrinsic apoptotic signaling pathway. In order to determine the involvement of the extrinsic apoptotic signaling pathway in FSB-induced apoptotic cell death in AGS cells, western blot analysis of extrinsic apoptotic signaling pathway proteins was performed in AGS cells. The western blot results identified that the expression of Fas and FasL were decreased by FSB treatment (Fig. 7A). In addition, the caspase- 8 activity assay results indicated that there was no activation of caspase-8 (Fig. 7B), which is one of the primary extrinsic apoptosis-associated proteins. These results indicate that there was no involvement of the extrinsic apoptotic signaling pathway in FSB-induced apoptotic cell death in AGS cells.

\section{Discussion}

Screening for natural compounds that are able to induce apoptosis in cancer cells is a promising emerging strategy for the treatment of cancer (17). Furthermore, natural pro ducts, such as traditional herbal medicines, which have fewer side effects compared with modern chemotherapeutics, have long been used clinically to treat various diseases, including cancer (18-20) Therefore, the identification of naturally occurring agents with pro-apoptotic activity in cancer cells is a promising approach for developing novel cancer chemotherapies. Although it has been demonstrated prev iously that the components of Korean S. baicalensis Georgi extract have distinct pharmacological properties, including anti-inflammatory and anticancer effects $(7,9)$, the underlying molecular mechanism of action of its antitumor property in gastric cancer remains largely unknown. To investigate the anticancer effects of FSB and its underlying molecular mechanism on AGS human gastric cancer cells, FSB, consisting of a mixture of 16 flavonoids, was isolated and characterized by HPLC-MS/MS, and used to assess its effect on the viability of AGS cells. FSB significantly inhibited AGS cell viability in a concentration-dependent manner and the $\mathrm{IC}_{50}$ was determined to be $\sim 100 \mu \mathrm{g} / \mathrm{ml}$. Morphological examination identified that a decrease in cell number and alterations in cell morphology, 
A

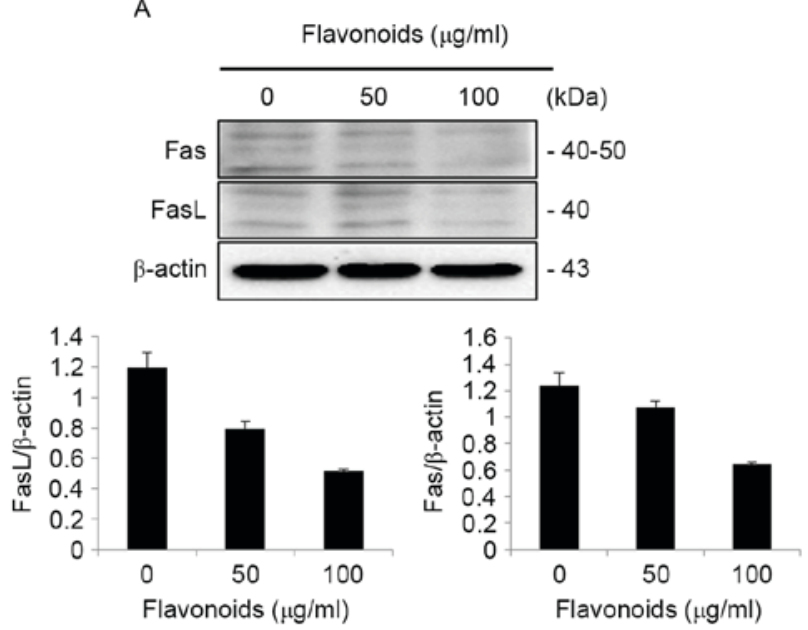

B

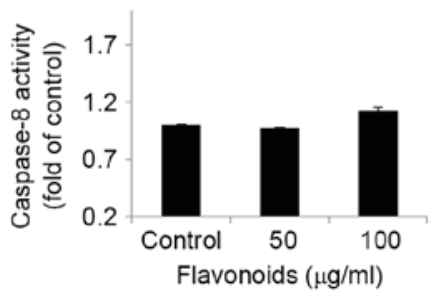

Figure 7. FSB-induced apoptosis in AGS cells is independent of the extrinsic apoptotic signaling pathway. (A) AGS cells were treated with the indicated concentrations of FSB for $24 \mathrm{~h}$. The cell lysates were subjected to SDS-PAGE and analyzed by western blotting. $\beta$-actin was used as loading control. Protein expression levels of Fas and FasL were determined using densitometric analysis. (B) Caspase-8 activities were determined using a colorimetric caspase-8 activity assay. FSB, flavonoid extract from Korean Scutellaria baicalensis Georgi; Fas, tumor necrosis factor regulator superfamily member 6; FasL, Fas ligand.

including cell shrinkage, were observed in FSB-treated cells, indicating apoptotic cell death.

Previous studies have indicated that various anticancer and chemo preventive agents, including natural compounds, exert anticancer effects via inducing apoptosis (type I programmed cell death) (21-23). We previously demonstrated that cell cycle aberrations frequently lead to apoptosis in various cell lines (24-27) In the present study, the accumulation of sub- $\mathrm{G}_{1}$ phase cells (indicating apoptosis) was identified in FSB-treated AGS cells in a concentration-dependent manner. Furthermore, Annexin V/FITC and PI staining confirmed apoptosis. These results are consistent with those of a number of previous studies on apoptotic cell death induced in various cancer cell lines $(26,28)$. Cleaved nuclei and apoptotic bodies, which are hallmarks of apoptosis, were identified in FSB-treated cells in the present study using Hoechest 33342 staining. These results revealed that FSB effectively suppressed AGS cells and induced apoptosis.

In apoptosis, caspases are key executioners of apoptosis that serve a critical role in drug-induced apoptosis in a variety of cancer cells. Members of this group of enzymes are known as 'initiator' and 'effector' caspases. Upon activation, extrinsic and intrinsic caspases, including caspase- 8 and caspase-9, respectively trigger the proteolysis activation of executioner caspases including caspase- 3 and caspase- 6 . In general, caspase- 3 is the common effector for the majority of apoptotic signaling pathways, and its active form is responsible for the cleavage of PARP and breakdown of a number of cellular components associated with DNA repair and regulation $(13,15,29,30)$. The results of the present study demonstrated that FSB significantly decreased the expression of procaspase- 3 and procaspase- 9 , and increased the expression of cleaved caspase- 3 and cleaved PARP. PARP is a nuclear DNA-binding zinc-finger protein which catalyzes the conversion of the dinucleotide nicotine-adenine dinucleotide into nicotinamide and protein-linked chains of ADP-ribose which leads to DNA fragmentation (31). The results of the present study demonstrated that there was no involvement of proteins associated with the extrinsic apoptotic signaling pathway, including Fas, FasL and caspase-8, and activation of caspase-8 in FSB-treated AGS cells.

Mitochondria serve an essential role in the propagation of apoptosis; evidence suggests that decreasing mitochondrial membrane potential is associated with mitochondrial dysfunction. Therefore, a decrease in mitochondrial membrane potential serves an important role during mitochondrially mediated apoptosis. The Bcl-2 family proteins are apoptotic regulatory proteins, which mediate the mitochondrial apoptotic process (32). The pro-apoptotic and anti-apoptotic proteins of Bcl-2 family in the cell determine whether a cell lives or dies. $\mathrm{Bcl}-\mathrm{xL}$ interacts with the mitochondrial plasma membrane and protects it from other apoptotic factors, including Bax and Bcl-2 homologous antagonist killer, thus preventing the release of cytochrome $c$ from the plasma membrane. Previous studies have demonstrated that flavonoids induce apoptosis in various tumor cell lines by inhibiting the overexpression of Bcl-2 family proteins $(26,33,34)$. The Bax/Bcl-xL ratio appears to be a factor that determines apoptosis. In the present study, it was observed that FSB treatment significantly decreased the mitochondrial membrane potential of AGS cells. In addition, Bcl-xL was significantly downregulated, whereas Bax protein levels were unchanged; however, the $\mathrm{Bax} / \mathrm{Bcl}-\mathrm{xL}$ ratio was upregulated in FSB-treated AGS cells. Cytochrome $c$ is able to bind to apoptotic protease-activating factor 1 when it is released from the mitochondria into the cytosol by increasing the $\mathrm{Bax} / \mathrm{Bcl}-\mathrm{xL}$ ratio, leading to the activation of caspase-3 and ultimately resulting in apoptosis. The results of the present study suggest that FSB-induced apoptosis in AGS human gastric cancer cells is via the mitochondrially mediated caspase-dependent intrinsic apoptotic signaling pathway.

The results of the present study indicate that FSB significantly inhibits cell viability and induces apoptosis in AGS cells via the mitochondrially mediated intrinsic apoptotic signaling pathway. FSB-induced apoptosis was identified to be mediated by caspase activation and triggered by the modulation of Bcl-2 family proteins. To the best of our know ledge, the present study is the first to elucidate the underlying molecular mechanism for the anticancer activity of FSB in human gastric cancer AGS cells. Therefore, the present study provides novel insights into the biological effects of FSB, which may possess therapeutic potential for the treatment of human gastric cancer.

\section{Acknowledgements}

The present study was supported by a grant from the National Research Foundation of Korea (NRF) funded by the Ministry of Science, ICT \& Future Planning (grant nos. 2012M3A9B8019303 and 2017R1A2B4003974). 


\section{References}

1. Torre LA, Bray F, Siegel RL, Ferlay J, Lortet-Tieulent J and Jemal A: Global cancer statistics 2012. CA Cancer J Clin 65: 87-108, 2015

2. Green D, Ponce de Leon S, Leon-Rodriguez E and Sosa-Sanchez R: Adenocarcinoma of the stomach: Univariate and multivariate analysis of factors associated with survival. Am J Clin Oncol 25: 84-89, 2002.

3. Ferlay J, Soerjomataram I, Dikshit R, Eser S, Mathers C, Rebelo M, Parkin DM, Forman D and Bray F: Cancer incidence and mortality worldwide: Sources, methods and major patterns in GLOBOCAN 2012. Int J Cancer 136: E359-E386, 2015.

4. Crew KD and Neugut AI: Epidemiology of gastric cancer. World J Gastroenterol 12: 354-362, 2006.

5. Harrison LE, Karpeh MS and Brennan MF: Extended lymphadenectomy is associated with a survival benefit for node-negative gastric cancer. J Gastrointest Surg 2: 126-131, 1998.

6. Liu HL, Jiang WB and Xie MX: Flavonoids: Recent advances as anticancer drugs. Recent Pat Anticancer Drug Discov 5: 152-164, 2010.

7. Park KI, Park HS, Kang SR, Nagappan A, Lee DH, Kim JA, Han DY and Kim GS: Korean Scutellaria baicalensis water extract inhibits cell cycle G1/S transition by suppressing cyclin D1 expression and matrix-metalloproteinase-2 activity in human lung cancer cells. J Ethnopharmacol 133: 634-641, 2011.

8. Yan H, Xin S, Wang H, Ma J, Zhang H and Wei H: Baicalein inhibits MMP-2 expression in human ovarian cancer cells by suppressing the $\mathrm{p} 38$ MAPK-dependent $\mathrm{NF}-\kappa \mathrm{B}$ signaling pathway. Anticancer drugs 26: 649-656, 2015.

9. Hong GE, Kim JA, Nagappan A, Yumnam S, Lee HJ, Kim EH Lee WS, Shin SC, Park HS and Kim GS: Flavonoids identified from Korean Scutellaria baicalensis Georgi inhibit inflammatory signaling by suppressing activation of $\mathrm{NF}-\kappa \mathrm{B}$ and MAPK in RAW 264.7 cells. Evid Based Complement Alternat Med 2013: 912031, 2013.

10. Kim JA, Nagappan A, Park HS, Saralamma VV, Hong GE, Yumnam S, Lee HJ, Raha S, Kim EH, Young PS and Kim GS Proteome profiling of lipopolysaccharide induced L6 rat skeletal muscle cells response to flavonoids from Scutellaria baicalensis Georgi. BMC Complement Altern Med 14: 379, 2014.

11. Kavandi L, Lee LR, Bokhari AA, Pirog JE, Jiang Y, Ahmad KA and Syed V: The Chinese herbs Scutellaria baicalensis and Fritillaria cirrhosa target $\mathrm{NF \kappa B}$ to inhibit proliferation of ovarian and endometrial cancer cells. Mol Carcinog 54: 368-378, 2015.

12. Taylor RC, Cullen SP and Martin SJ: Apoptosis: Controlled demolition at the cellular level. Nat Rev Mol Cell Biol 9: 231-241, 2008.

13. Saraste A and Pulkki K: Morphologic and biochemical hallmarks of apoptosis. Cardiovasc Res 45: 528-537, 2000.

14. Hacker G: The morphology of apoptosis. Cell Tissue Res 301: 5-17, 2000.

15. Logue SE and Martin SJ: Caspase activation cascades in apoptosis. Biochem Soc Trans 36: 1-9, 2008.

16. Cory S and Adams JM: The Bcl2 family: Regulators of the cellular life-or-death switch. Nat Rev Cancer 2: 647-656, 2002.

17. Hanahan D and Weinberg RA: Hallmarks of cancer: The next generation. Cell 144: 646-674, 2011.

18. Ademosun AO, Oboh G, Passamonti S, Tramer F, Ziberna L, Boligon AA and Athayde ML: Inhibition of metalloproteinase and proteasome activities in colon cancer cells by citrus peel extracts. J Basic Clin Physiol Pharmacol 26: 471-477, 2015.
19. Ye F, Jiang S, Volshonok H, Wu J and Zhang DY: Molecular mechanism of anti-prostate cancer activity of Scutellaria baicalensis extract. Nutr Cancer 57: 100-110, 2007.

20. Newman DJ and Cragg GM: Natural products as sources of new drugs over the 30 years from 1981 to 2010. J Nat Prod 75: 311-335, 2012.

21. Ubah OC and Wallace HM: Cancer therapy: Targeting mitochondria and other sub-cellular organelles. Curr Pharm Des 20: 201-222, 2014.

22. Danial NN and Korsmeyer SJ: Cell death: Critical control points. Cell 116: 205-219, 2004.

23. Fesik SW: Promoting apoptosis as a strategy for cancer drug discovery. Nat Rev Cancer 5: 876-885, 2005.

24. Zhang L, Cheng X, Gao Y, Zheng J, Xu Q, Sun Y, Guan H, $\mathrm{Yu} \mathrm{H}$ and Sun Z: Apigenin induces autophagic cell death in human papillary thyroid carcinoma BCPAP cells. Food Funct 6: 3464-3472, 2015

25. Nagappan A, Lee HJ, Saralamma VV, Park HS, Hong GE, Yumnam S, Raha S, Charles SN, Shin SC, Kim EH, et al: Flavonoids isolated from Citrus platymamma induced $\mathrm{G} 2 / \mathrm{M}$ cell cycle arrest and apoptosis in A549 human lung cancer cells. Oncol Lett 12: 1394-1402, 2016.

26. Lee DH, Park KI, Park HS, Kang SR, Nagappan A, Kim JA, Kim EH, Lee WS, Hah YS, Chung HJ, et al: Flavonoids isolated from Korea Citrus aurantium L. induce G2/M phase arrest and apoptosis in human gastric cancer AGS cells. Evid Based Complement Alternat Med 2012: 515901, 2012.

27. Park KI, Park HS, Nagappan A, Hong GE, Lee DH, Kang SR, Kim JA, Zhang J, Kim EH, Lee WS, et al: Induction of the cell cycle arrest and apoptosis by flavonoids isolated from Korean Citrus aurantium L. in non-small-cell lung cancer cells. Food Chem 135: 2728-2735, 2012.

28. Saralamma VV, Nagappan A, Hong GE, Lee HJ, Yumnam S, Raha S, Heo JD, Lee SJ, Lee WS, Kim EH and Kim GS: Poncirin induces apoptosis in AGS human gastric cancer cells through extrinsic apoptotic pathway by up-regulation of fas ligand. Int $\mathrm{J}$ Mol Sci 16: 22676-22691, 2015.

29. Stennicke HR and Salvesen GS: Properties of the caspases. Biochim Biophys Acta 1387: 17-31, 1998.

30. Kumar S: Regulation of caspase activation in apoptosis: Implications in pathogenesis and treatment of disease. Clin Exp Pharmacol Physiol 26: 295-303, 1999.

31. Tait SW, Ichim G and Green DR: Die another way-non-apoptotic mechanisms of cell death. J Cell Sci 127: 2135-2144, 2014.

32. Tait SW and Green DR: Mitochondria and cell death: Outer membrane permeabilization and beyond. Nat Rev Mol Cell Biol 11: 621-632, 2010.

33. Hyun HB, Lee WS, Go SI, Nagappan A, Park C, Han MH, Hong SH, Kim G, Kim GY, Cheong J, et al: The flavonoid morin from Moraceae induces apoptosis by modulation of Bcl-2 family members and Fas receptor in HCT 116 cells. Int J Oncol 46: 2670-2678, 2015.

34. Zhang SD, Shan L, Li W, Li HL and Zhang WD: Isochamaejasmin induces apoptosis in leukemia cells through inhibiting Bcl-2 family proteins. Chin J Nat Med 13: 660-666, 2015. 